\title{
EL CONCEPTO DE INGENIUM CICERONIANO
}

Javier Espino Martin*

RESUMEN: El ingenium representa un medio fundamental para entender la retórica ciceroniana y, sobre todo, se convierte en el principal instrumento para entender la retórica barroca de la Compañía de Jesús. En el presente artículo analizamos cómo el ingenium puede ser una herramienta hermenéutica para comprender el paso de la retórica clásica ciceroniana a la jesuítica gracias al entorno ideológico e historiográfico del periodo contrarreformista.

$$
\text { গ৯e }
$$

\section{CICERO'S CONCEPT OF INGENIUM}

ABSTRACT: Ingenium is a key concept to understand Ciceronian rhetoric and the central tool to understanding the Baroque rhetoric of the Company of Jesus. In this article, we will analyze how this concept can be a hermeneutic tool to comprehend the progression of classic Ciceronian rhetoric to that of the Jesuits thanks to the ideological and historiographic atmosphere of the Counter-Reformation period.

PALABRAS CLAVE: ingenium, retórica, Cicerón, hermeneútica, sociología.

KEY WORDS: ingenium, rhetoric, Cicero, hermeneutics, sociology.

RECEPCIÓN: 17 de marzo de 2016.

APROBACIÓN: 11 de agosto de 2016.

* Universidad Nacional Autónoma de México, Instituto de Investigaciones Filológicas, Centro de Estudios Clásicos. 



\section{EL CONCEPTO DE INGENIUM CICERONIANO*}

\section{Introducción}

$\mathrm{E}_{\text {lingenium constituye un instrumen- }}$ to que permite distinguir dos modos de concebir y analizar la realidad: el modus rhetoricus y el modus philosophicus. Si el ingenium se erige como principal cimiento del primero, la "deducción" o el "apotegma" lo es del segundo. Precisamente, el orador romano Cicerón empleará el ingenium como una base alternativa al aristotelismo filosófico de observar la realidad e interactuar con ella. Será el arma jurídica y retórica para su visión ética y política de la filosofía. Posteriormente, en el barroco se empleará como arma ideológica y espiritual para interpretar tanto el catolicismo como la sociedad. De la interpretación del pensamiento barroco-jesuita pasaremos a la que aporta la mentalidad

* Este artículo se inscribe en el proyecto de investigación para el desempeño de la plaza de Profesor Asociado "C" del Centro de Estudios Clásicos en el Instituto de Investigaciones Filológicas, Universidad Nacional Autónoma de México, con el título: "Literatura latina y estéticas de la modernidad. Recreación, crítica y lectura de los clásicos en los siglos XVIII, XIX y XX". Por otro lado, este proyecto sirve de base para los estudios que hemos realizado en nuestro proyecto de investigación PAPIIT (Programa de Apoyo a Proyectos de Investigación e Innovación Tecnológica de la UNAM), clave IA400915, con título: "Recepción clásica y modernidad. Autores de la antigüedad clásica en la configuración del pensamiento ilustrado y romántico". 
ilustrada, que basa sus premisas en el control equilibrado de la ratio y del decorum, también conceptos del ámbito ciceroniano. De este modo, contrastaremos ambas cosmovisiones a partir del concepto de ingenium según el pensamiento y la retórica en Cicerón, estudiados a la luz de la oposición de dos modelos de interpretar la realidad antitéticos: el barroco-jesuita y el racionalista ilustrado.

\section{El ingenium en el pensamiento retórico ciceroniano}

Para entender cómo plantea Cicerón el ingenium retórico hemos de partir de dos modos de concebir la enseñanza y la forma de comprender el mundo en la antigüedad, desde la época helenística (siglo IV a. C.). Básicamente, había dos métodos de interpretar y analizar la realidad humana: el método retórico (modus rhetoricus) y el método filosófico (modus philosophicus, posteriormente scholasticus). El primero era el defendido por sofistas, por retóricos como Isócrates y luego por las escuelas helenísticas. El segundo era más elitista y lo practicaban los grandes filósofos como Platón, Aristóteles o los teólogos y escolásticos medievales. ${ }^{1}$ El que se contrastaran estos métodos no significa que fueran totalmente antitéticos, sino que había muchos cruces zigzagueantes entre ambos, de modo que los filósofos tenían en cuenta la retórica como buen "trampolín" para expresar sus propios estudios e investigaciones y, viceversa, para los retóricos la filosofía aportaba un soporte de virtudes éticas que encaminaba adecuadamente el aparato retórico, de forma que no quedara únicamente como mero adorno sin contenido ni propósito.

Precisamente, la retórica romana es heredera directa de ese modus rhetoricus sofista y helenístico que tiene a Isócrates como su principal garante. ${ }^{2}$ Según esto, si nos centramos en el modo que tenían los romanos

${ }^{1}$ Se encuentra un panorama histórico y analítico de ambos métodos en la primera parte del estudio clásico de Marrou sobre la educación en la antigüedad, Historia de la educación en la Antigüedad, 2004, México, Fondo de Cultura Económica, pp. 88-268.

${ }^{2}$ No en vano el propio Cicerón, en su De oratore (2.3.10, [Cicerón, De oratore, 2002, Madrid, Gredos, intr., trad. y notas de José Javier Iso, p. 207]) lo cita como "padre de la elocuencia", cuando aconseja a su hermano cómo debe hablar siguiendo los modos retóricos. 
de concebir la retórica, esta es dinamismo, es vida, forma parte del ser humano, fusiona la realidad exterior y la interior, es una paideía, una forma de concebir el universo que se diferencia del modus scholasticus o philosophicus de Platón, Aristóteles o los estoicos. Por eso mismo, Cicerón plantea ideas y pensamientos que servirán de base para el último peldaño de ese logos rhetoricus (que se metamorfoseará, como veremos, en el logos ingenii de Gracián). Dentro de ese logos rhetoricus, la elocutio constituye su esencia básica, ya que para Cicerón esta no es tanto el simple "adorno" de las palabras y sentencias del discurso, sino que es una forma de percibir la realidad y la sociedad que interactúan. En especial, para Cicerón la elocutio ha de servir al interés colectivo y no subordinarse a intereses personales, como sucedía con la retórica sofista. La elocutio se valdrá del ingenium y de todas las figuras que se desarrollan en él y que serán como vasos conductores de este, que organizan el vasto edificio de la elocutio retórica. En el siguiente pasaje del libro III del De oratore apreciamos claramente la idea que tiene Cicerón de cómo se constituye la elocutio, como tal:

En cuanto al discurso en sí — como ocurre con las armas-, unas veces se usa para amenazar y hasta para atacar, y otras su manejo tiene como finalidad la exhibición en sí. Pues la repetición de palabras unas veces es muestra de vigor y otras de encanto; y una palabra que cambia y se debía ligeramente; y la frecuente repetición de una misma palabra, unas veces al comienzo y otras invirtiendo su posición al final; y el atacar con las mismas palabras, y el concentrarlas y el acumularlas y el intensificarlas; y el diferenciar significados de una misma palabra en su uso repetido; y aquellas que tienen el mismo sufijo o la misma desinencia; o las que se corresponden, ya por ser de dimensión o estructura semejantes.

Está también el clímax y la metátesis y la transgresión del orden de palabras que resulta eufónica y la antítesis y el asíndeton y la preterición, el corregirnos sobre la marcha, las exclamaciones, y el minimizar la cosa y lo que se presenta en casos distintos, y lo que, cogido de cada uno de ellos, el añadir una razón vuelve a llevarse a cada uno de ellos, el añadir una razón a lo previamente expuesto o igualmente al enumerar una razón distinta para cada hecho, o cuando nos ponemos totalmente en manos del auditorio, o se expresan dudas sobre el término a usar, o algo que nadie 
espera, y la enumeración y otro tipo de precisión, la distribución por lugares, y una serie de preguntas ininterrumpidas, o un vívido símil, y cuando uno se responde a sí mismo y la metonimia y el tratamiento por separado de los distintos miembros y su disposición adecuada y la relación y la digresión y la perífrasis. Estos son poco más o menos $-\mathrm{y}$ parecidos a estos puede haber incluso muchos más - los procedimientos que iluminan el discurso mediante el pensamiento y las disposiciones de palabras. ${ }^{3}$

En el pasaje anterior, Cicerón explicita todas las figuras que a modo de "armas" del discurso nacen del ingenium, con el fin de iluminar dicho discurso, pero siempre "mediante el pensamiento y las disposiciones de palabras". Por lo tanto, Cicerón considera que el ingenium es imprescindible para la estructuración de las "sentencias", propias de la elocuencia. ${ }^{4}$ Esta forma de ver la realidad desarrolla un "arte de invención" (ars inveniendi) del discurso que rechaza o se opone al "de demostración" (demostrandi) propio de la filosofía: si este último tiene al "silogismo" como principio básico, el retórico tiene al ingenium como cimiento imprescindible (potenciado, a menudo, por la diligentia). ${ }^{5}$

El "arte de invención" (inventio), en la que se elabora el ingenio, permite ver el lado oculto y auténtico de la res a través de un lenguaje humano y no de un lenguaje lógico y artificial ajeno al hombre. ${ }^{6}$ Ese lenguaje se expresa mediante figuras retóricas que gravitan en torno a la más importante de todas ellas, la "analogía" o "metáfora". Tanto

${ }^{3}$ Cicerón, op. cit., 3.54.206-208, p. 480.

4 "Como la elocuencia consta de palabras y sentencias, se ha de procurar, no solo la pureza latina, sino la elegancia de las palabras propias y trasladadas, eligiendo entre las propias las mejores y siguiendo en las traslaciones la semejanza. Hay tantos géneros de sentencias como de cualidades dijimos que había en la oratoria. Las sentencias en que se trata de enseñar son agudas; las que deleitan, ingeniosas, las que conmueven graves"; Opt Gen. 2.5 (Cicerón, "Del mejor género de oradores", en Dámaso López García (ed.), Teorías de la traducción. Antología de textos, 1996, Universidad de Castilla-La Mancha, Cuenca).

5 "En suma, siendo tres los factores para hallar argumentos en el discurso: a saber, la agudeza, a continuación el método — que, si lo queremos, podríamos llamar arte- y en tercer lugar, la diligencia, lo cierto es que no puedo dejar de asignar la primacía a la inteligencia. Sin embargo, es la diligencia la que incluso desde una falta de agudeza espolea a la inteligencia misma; diligencia que, por decirlo una vez más, siendo muy importante en cualquier cosa, lo es en particular en la defensa de una causa"; De orat. 2. 35.148; ibid., p. 269.

${ }^{6} \mathrm{La}$ inventio hace la res, aplicando la terminología kantiana, "fenomenológica". 
Cicerón como el jesuita Gracián defienden la plasticidad de la metáfora y su capacidad de penetrar en el conocimiento de la realidad, ya que supone "un rasgo de originalidad" porque "el que escucha se traslada a otro lugar con el pensamiento" o "porque en una sola palabra se funden la cosa y la comparación entera". ${ }^{7}$ Cicerón (al igual que en los Ejercicios Espirituales de San Ignacio) muestra su predilección por "las metáforas que afectan a la vista”, ya que "son mucho más vívidas, pues poco menos que ponen ante los ojos del alma lo que no podemos contemplar o ver. Pues nada hay en la naturaleza que no podamos nombrar ni mentar en conexión con otras cosas". La metáfora acaba volviéndose una necessitas propia del ingenio humano que combina la percepción sensorial y el discurso, de modo que a través de las metáforas se produce una combinación entre referentes distintos que se unen mediante el lenguaje metafórico, lo que acaba proporcionando placer tanto sensorial como intelectivo. ${ }^{8}$ De este modo, el ingenium permite, a través del uso translaticio de la metáfora, ver las similitudines de las cosas, ${ }^{9}$ de forma que nos proporcionan un completo y exacto conocimiento (un saber "horizontal" frente al "vertical" de la filosofía), acompañado con un intenso disfrute sensorial. Ambos superan con creces el conocimiento parcial y rudo de la filosofía que divide mente y cuerpo.

\section{El ingenium como hermenéutica social ciceroniana}

El ingenium, según lo visto en el apartado anterior, desarrolla un juego verbal de "metáfora ingeniosa" que se insertará en la res ("el hecho, la cosa, el estado"), lo que permitirá descubrir su esencia, pero "solo en

${ }^{7}$ José Javier Iso (Cicerón, op. cit., p. 249, n. 236), glosando a Leeman destaca la importancia de estas afirmaciones porque en ellas se comprueba que la metáfora va más allá de ser un mero ornato y es "un modo, en fin, de conocimiento más rico y sugerente que el habitual", ya que resulta imprescindible para "aportar luz al discurso".

8 "Y en este terreno a menudo me resulta admirable el porqué todos sienten más placer con palabras traídas de otro sitio y ajenas que con las suyas propias"; De orat. 3.39.159, ibid., p. 269.

${ }^{9}$ E. Grassi, El poder de las fantasías: Observaciones sobre la historia del pensamiento occidental, 2003, Barcelona, Anthropos, p. 208. 
el marco de la comunidad social, política". ${ }^{10}$ De este modo la res se vuelve res publica que da al ser humano el "sentido profundo de su labor". ${ }^{11}$ Es la experiencia de la vida cotidiana la que da a Cicerón el verdadero sentido del conocimiento y no de las abstracciones lógicas o filosóficas. El solo "sentido común" hunde sus raíces en la "labor ingeniosa" de la experiencia cotidiana del ser humano que desarrolla y se fusiona en su contexto histórico-político y, aunque no nos da definiciones universales, sí aporta un conocimiento más real de la vida humana. ${ }^{12}$ Por eso mismo, a partir de la viveza que da a las sentencias de la elocución, el ingenium se convierte en el motor que desarrolla, según denomina Cicerón en sus Disputaciones Tusculanas, los semina virtutum ("semillas de virtudes"). ${ }^{13}$ Por esto, el ingenium, mediante su instrumento metafórico, tendrá un valor no solo discursivo, sino netamente ético y político. Curiosamente, esa realidad más vivida e instantánea del hombre ciceroniano es movediza, inconstante, opuesta a la verdad científica estática de los filósofos. Se trata de una realidad verosímil frente a la verdad exacta del pensamiento lógico. No obstante, para el orador romano es más auténtica la verdad verosímil del pensamiento elocutivo e ingenioso que la "exacta" y "científica" del pensamiento filosófico y lógico:

En cambio, las posibilidades de la elocuencia son tales, que puede abarcar el origen, la esencia y los cambios de todas las cosas, las virtudes y la naturaleza de la que dependen el carácter, el espíritu y la vida del hombre; y al mismo tiempo, puede establecer costumbres, leyes y

${ }^{10}$ Ibid., p. 209.

${ }^{11}$ Loc. cit.

${ }^{12}$ Este pensamiento que huye de la abstracción generalizadora y se regodea en lo concreto y en lo particular, responde mucho a la mentalidad pragmática romana, que queda ampliamente de manifiesto en la formación de su sistema jurídico, que se distingue por su "carácter casuístico" y sus grandes "cautelas contra todo lo que sea abstracción, definición, construcción y sistematización”; véase G. Radbruch, Introducción a la filosofía del derecho, 1951, México, Fondo de Cultura Económica, p. 66.

13 "En efecto, están innatas en nuestra índole las semillas de las virtudes, que si pudieran desarrollarse, la naturaleza misma nos conduciría a la vida dichosa"; Tusc. 3.1.2.; Disputas Tusculanas, 2008, México, Bibliotheca Scriptorum Graecorum et Romanorum Mexicana, Universidad Nacional Autónoma de México, intr., trad. y notas de Julio Pimentel Álvarez, p. 97. 
principios jurídicos, dirigir la vida pública y exponer con elegancia y abundancia cualquier tema, sea cual sea su orientación. ${ }^{14}$

\section{El ingenium constituye el foco de dos fuerzas imprescindibles del} ser humano: por un lado, el conocimiento verdadero de la res, en su papel verosímil y probable, no en el misterioso que desarrolla el lenguaje lógico y filosófico; por otro lado, constituye la raíz de nuestras "virtudes" (virtutes), entre las que destaca la "confianza" o fides, ${ }^{15}$ la más social de todas, y el "trabajo" (labor). ${ }^{16}$ Las primeras son de carácter espiritual y la segunda material, pero ambas constituyen el "pegamento social", el medio por el que nos unimos socialmente entre nosotros mismos y con las "cosas" (las res). ${ }^{17}$ Las virtutes nacen del ingenium para conseguir juntarnos en un cuerpo social político (la res publica); labor será el papel que nuestra historicidad desempeña en ese cuerpo social; por último, fides comunica la laboriosidad entre todos los ciudadanos en la jerarquía que corresponde y permite que no se disuelva la concordia social. Podría ser sinónimo de "pacto de la sociedad"18 que se basa, inevitablemente, en la confianza entre sus integrantes. La forma de "comprender" (intelligere) y ahondar "comprensivamente" todo este entramado se logra a través de las palabras (verba) metafóricas que tienen su relación directa con la res y saca de su interior la "verdad

${ }^{14}$ Cicerón, 3.20.76, p. 409

${ }^{15}$ La fides es inicialmente confianza de unos con otros, por eso es una virtud especialmente social y jurídica que se manifiesta en el concepto de bona fides (Radbruch, op. cit., p. 67). Posteriormente, por evolución fonética se convertirá en "fe", pero seguirá manteniendo su contenido semántico primario, ya que la confianza se trasladará de social entre hombres, a metafísica con Dios.

${ }^{16}$ El labor será muy importante en el mundo romano y en el pensamiento protestante, que en alemán se denominará Beruf y que considerará que, más allá de la fides, la forma que tiene el ser humano de unirse con Dios será principalmente a través del "trabajo".

${ }^{17}$ En la siguiente afirmación del Bruto (Brut. 15.59; Bruto. De los oradores ilustres, 2004, México, Bibliotheca Scriptorum Graecorum et Romanorum Mexicana, Universidad Nacional Autónoma de México, intr., trad. y notas de Bulmaro Reyes Coria, p. 21), se puede observar la importancia del hombre que posee ingenium en cuanto a su relación con la societas: "pues, como el decoro del hombre es el ingenio, así la lumbre del ingenio mismo, la elocuencia; y aquellos hombres entonces dijeron que el varón que sobresalía muy claramente en ésta, era la flor del pueblo, la médula de Suada".

${ }^{18}$ Más adelante, las teorías "contractualistas" reivindicarán ese "pacto social” basado en la fides, como en Rousseau, tan influido por la política clásica. 
social" (o mejor dicho, "verosimilitud social") ${ }^{19}$ que permite, precisamente, la unión de sus miembros.

El ingenium solo puede manifestarse a través de los verba. Uno de los rasgos que identifica esa combinación res-verba lo constituye la "rapidez" (celeritas) de aprehender capciosa e instantáneamente la realidad. Así pues, esa celeritas nos revela la realidad profunda y súbita de la realidad..$^{20}$ La realidad es movediza, inconstante y fugaz, frente a esa realidad estereotipada, rígida y estática de los filósofos. Consciente de esa "velocidad" que transmite fielmente la metáfora y el ingenium, de la que no se percata el método filosófico, se requiere, sin embargo, que este modo de expresar la realidad sea equilibrado por una dispositio basada en la prudencia:

Y al estar dividida en cinco apartados la fuerza y la habilidad del orador, que en primer lugar tenía que encontrar lo que tenía que decir, seguidamente distribuir y colocar lo hallado no solo con orden sino con un cierto ritmo y prudencia; y por fin revestir y adornar entonces el discurso; tras ello, afianzarlo con la memoria y por último ejecutarlo con decoro y donaire. ${ }^{21}$

Así pues, la dispositio ha de seguir un ordo que tiene como principios rectores el iudicium (reflexión o juicio acorde a la ley), el momentum (momento, instante), la memoria (memoria), la venustas (gracia, encanto, Iso lo traduce por "donaire") y la dignitas (belleza con merecimiento, o mérito y estima). ${ }^{22}$ Según se puede apreciar, ninguno de los elementos que permiten "adornar" (en el sentido de "ordenar" un discurso), se guía por la ratio o el logos, sino que son elementos que

${ }^{19}$ La búsqueda de esa verdad oculta también va a ser obsesión del pensamiento romántico, que en su indagación formará constructos ideológico-políticos, como el "nacionalismo" o el "comunismo". Véase G. L. Mosse, La cultura europea del siglo XIX, 1997, Barcelona, Ariel, p. 18.

20 "Pues debe haber una cierta rapidez de reflejos en el espíritu y en el ingenio, mostrándose así agudos para la imaginación, ricos para la exposición y el ornato y firmes y duraderos para la memoria"; De orat. 1.25.113, p. 131.

${ }^{21}$ De orat. 1.31 .142 , p. 141.

${ }^{22} \mathrm{Hemos}$ seguido las definiciones del diccionario bilingüe latín-español de Julio Pimentel, cuyo título completo es Diccionario Latín-Español, Español-Latín. Vocabulario clásico, jurídico y eclesiástico, 2009, México, Porrúa. 
forman un juicio (iudicium) paralelo a estos, dado que, como hemos dicho, el método retórico se rige por otros mecanismos, no lógicos, que controlan y demarcan el ingenium. ${ }^{23}$

En definitiva, la inventio que se desarrolla en el ingenium y en la metáfora ha de estar delimitada por el orden equilibrador de la dispositio que responde a un buen gusto o decoro. En este punto vemos que Cicerón se acerca al concepto poético de Aristóteles que establecía que la inventio había de aplicarse "en cambio, con moderación" (modice tamen $)^{24}$. Pero si para Aristóteles la moderación se establece por la reflexión y la ratio, de base estrictamente lógico-filosófica, Cicerón lo hace desde el decorum y el ornatus, por lo que su fundamento es estrictamente retórico-social. Si bien ambos coinciden en el equilibrio de la desmesura del ingenium, difieren porque el Estagirita tiene a la ratio como elemento moderador. Cicerón, sin embargo, emplea el ornatus y el decorum (que proviene del verbo decet: "lo que conviene"), una especie de "juicio o espíritu estéticos", que nacen de una intuición propiamente humana que conlleva, además, connotaciones ético-políticas y no estrictamente lógicas o filosóficas. Los humanistas del Renacimiento supieron ver este decorum adecuadamente, aunque a veces lo confundían con la ratio. Sin embargo, ya en pleno racionalismo del XVIII se acabó identificando el decorum con la ratio aristotélica, supeditando la creación literaria a la reflexión filosófica. Este concepto ciceroniano del decorum será muy importante tenerlo en cuenta, ya

${ }^{23}$ En el libro III "Del orador", Cicerón nos dice que para ordenar el discurso se exige "un cierto ritmo y equilibrio", de forma que la colocación y orden de palabras no resulte "áspero ni con hiatos sino ligero y en cierto modo fluido"; De orat. 3.43.171, p. 171.

${ }^{24}$ Ratio 1599, citado en E. Gil Coria, La pedagogía de los jesuitas, ayer y hoy, 1999, Madrid, Universidad Pontificia de Comillas, p. 160. A este respecto, son ilustrativas las palabras de M. Batllori (Gracián y el barroco, 1958, Roma, Edizioni di storia e letteratura, pp. 110-111): "Todo ello supuesto, el problema del paso de la retórica de la Ratio a la retórica jesuítica del pleno barroco, es el mismo problema del tránsito de la retórica aristotélica a la retórica barroca en general. No son los principios clásicos de la mímesis y de la catharsis los que permiten esa evolución. Los portillos de escape fueron los tópicos o figuras, el ingenio, la invención. Aristóteles los alaba y encomia, pero los recomienda con moderación, en proporción debida con las restantes partes del discurso. Lo mismo hace la ratio jesuítica, tanto en la parte general, como en el ejercicio de los "emblemas" en particular. Bastó perder el sentido de la medida —y en esto radica la esencia del Barroco- para desbocarse por el sendero del barroquismo". 
que los jesuitas barrocos como Gracián supieron interpretar el pensamiento ciceroniano, aunque lo acabaron retorciendo en su afán de exprimir su base no filosófica.

Para Cicerón ese ingenium o la "agudeza de mente" que se establece sobre la armonía del decorum se adquiere mediante la "templanza" (temperantia) y la "moderación" (moderatio). ${ }^{25}$ Es interesante destacar que "lo ingenioso" se configura mediante el decoro, tanto en su vertiente estética como en su vertiente ética, que le confieren esa "moderación" y "templanza", bases de la "honestidad" (honor y honestitas). Ese decoro, en última instancia, proviene de una ratio que se establece como una ratio paralela a la lógica del método filosófico y aristotélico: sería, pues, una ratio decorosa. Ese decorum nace de la propia natura y una vez que configura el ingenium, este tiene como prioridad mantener la sociedad unida. Por lo tanto, el decorum sería un elemento natural y el ingenium social; pero para que el ingenium funcione ha de ser moderado por la "ratio decorosa" que hemos mencionado.

De ese modo, con el "ingenio" la sociedad se mantiene en orden (aunque para llegarlo a tener es necesario que previamente la sociedad haya estado en orden). Para Cicerón, el elemento que une al hombre con la naturaleza (natura) es el decoro:

Pero el deber que procede del decoro nos lleva ante todo a vivir en armonía y a la observación de las leyes. Si tomamos esta naturaleza por guía, nunca nos alejaremos del recto camino y conseguiremos la natural perspicacia y agudeza de la mente, una conducta conforme a la convivencia civil, y fuerza y vigor de carácter. Pero la mayor fuerza del decoro reside esta parte de la que estamos hablando. Y no solamente hay que probar los movimientos del cuerpo, que se realizan conforme a la naturaleza, sino mucho más los sentimientos del alma, cuando están igualmente acomodados a la naturaleza. ${ }^{26}$

Para que el decoro se reafirme en el ser humano, se logra con dos cualidades que lo constituyen: la moderación y templanza ("el decoro

${ }^{25}$ Cicerón, Off. 1.28.98-100, Sobre los deberes, 1989, Madrid, Tecnos, trad. de José Guillén Cabañero, p. 100.

${ }^{26}$ Off. 1.28 .100$, p. 52. 
especial es — según definen - lo que es tan conforme con la naturaleza que en él aparecen la moderación y la templanza unidas a los modales de una educación perfecta"). ${ }^{27} \mathrm{El}$ ingenium, por lo tanto, tiene una raíz interna en el decorum que lo nutre, pero también ha de tener manifestaciones externas para que se concrete y se realice: estas son las citadas fides y el labor:

En este sentido debemos seguir a la naturaleza como guía, poniendo en común lo que puede ser útil a todos en el intercambio de servicios, dando y recibiendo, y hacer más íntima la sociedad de los hombres entre sí con nuestro ingenio, con nuestro trabajo y todos los medios de que dispongamos. ${ }^{28}$

Por todos estos factores que se desarrollan en torno al ingenium y que constituyen el edificio de la elocutio retórica, se aprecia que esta es un elemento estrictamente social que aun naciendo de la naturaleza que insufla la ratio decorosa, la supera y la perfecciona, hasta el punto que "domina la naturaleza" y "empuja al auditorio donde se le propone". Por este motivo, es vista como una "facultad mayor" que por eso mismo "ha de estar más unida a la honradez y a una extraordinaria prudencia". ${ }^{29}$

Según esto, la sociedad (societas) y la res pública son el producto final de una elocutio bien desarrollada por el ingenium. Por ello se superpone a la natura, y aunque se basa en ella, la domina. Cicerón intenta explicar que el modo en que las fuerzas del ingenium y de las virtutes engrandecen el alma y la admiración ${ }^{30}$ permiten desarrollar un entorno social político como el romano. A pesar de que ese ingenium social domine la natura, Cicerón, siempre imbuido de su espíritu ecléctico, concibe que para que ello se lleve a buen término como en el caso de la sociedad romana es necesario un poder superior que vele por que todo ese complicado proceso de formar una sociedad recta y "elocutiva" se configure adecuadamente y sin tropiezos ni obstáculos. Ahí podemos

${ }^{27}$ Off. 1.27 .96$, p. 50.

${ }^{28}$ Off. 1.7.22, p. 15 .

${ }^{29}$ De orat. 3.14 .15 , p. 397.

${ }^{30}$ De orat. 2.84 .344 , p. 344 . 
apreciar cierta incongruencia con su pensamiento que nacía radicalmente social y poco dado a derivas místicas. De este modo, esa inspiración o espíritu ingenioso que nace del decorum de la natura, a su vez, tiene que venir de algo más alto a todo ello, una fuerza divina, un deus que al ser tan grande lo llamamos $d e i .{ }^{31}$ En este pensamiento se puede apreciar la huella tan importante del estoicismo, aunque Cicerón lo vuelve social y político y lo aleja de la perspectiva filosófica.

\section{La recepción del ingenium ciceroniano en la dicotomía del pensamiento barroco e ilustrado}

Es interesante repasar brevemente el impacto que el ingenium ciceroniano tendrá en el pensamiento moderno. Si bien durante el Renacimiento el concepto se ensancha y amplía sus atribuciones, puesto que adquiere una naturaleza "artificiosa" progresiva, en el barroco, y en concreto con la labor educativa y cultural jesuita, el ingenium se transforma en el símbolo de la cosmovisión barroca.

Debido a un potenciamiento sustancial de conceptos como la imaginatio o la phantasia, a través del oculus mentis en los Ejercicios Espirituales (1548) de San Ignacio, el ingenium se vuelve el centro del "misticismo sensorial" del santo. Será el ingenium el centro y corazón para desarrollar esa compositio loci en la que el fiel tiene que sentir, en gran medida, la presencia real de Cristo y de los personajes del Evan-

${ }^{31}$ Otro tema digno de estudio sería la figura del deus en Cicerón, que en su obra Cuestiones académicas, siguiendo la línea escéptica y estoica, presenta la idea de un deus deceptor que se mueve entre el mundo real y el probable. La crítica ha señalado su gran semejanza con el genio maligno o el Deus fallax cartesiano. Al respecto, véase la teoría de B. García Hernández ("El deus deceptor de las Cuestiones académicas de Cicerón y de Descartes", Revista de Estudios Latinos, 6, 2006, pp. 167-183), que expone estas teorías y desarrolla la propia en la que ve mayor semejanza entre el Deus cartesiano y el Anfitrión de Plauto. Nosotros también vemos la correspondencia de ese Deus ciceronianus con el Deus jesuítico, ya que al igual que Cicerón propone una Deus ecléctico, a medio camino entre la falsedad y la veracidad, un Dios del probabilismo, a través del concepto de scientia media, el Deus jesuítico de Molina y sus seguidores se presenta como un Dios mediador entre el hombre y un Dios plenamente omnipotente, que sería el Dios de la Gracia, que defienden los protestantes. Véase B. Echeverría, La modernidad de lo barroco, 2000, México, Era, pp. 74-80. 
gelio a través de la "sensorialización" de los episodios de su vida (lo que San Ignacio define como "composición viendo el lugar"). ${ }^{32}$ El creyente ve, escucha, percibe con todos sus sentidos las escenas de la vida y de la Pasión de Cristo, así como siente los padecimientos del infierno si peca; por eso los Ejercicios "instan a "imaginar" y no a "memorizar". ${ }^{33}$ A partir de ahí, se deberá acudir al uso de la imaginatio y de la phantasia, que adquieren en el misticismo de San Ignacio una especial fuerza. Ambos factores potenciarán notablemente la sensibilidad de todos los sentidos del creyente, con el propósito de interiorizar los cuadros religiosos que se le presentan. ${ }^{34}$ La natura ilumina el ingenium del iniciado mediante los afectos sensoriales que son el puente de unión entre la creación natural divina y el cuerpo humano que palpita gestualmente en furor místico, porque gracias a esa conexión, el ingenium ha entendido de modo "afectivo y emocional la expresión divina". Basándose en estos principios del misticismo ignaciano, el jesuita barroco pretende traer al mundo cristiano pasajes de la vida de Cristo a través de las expresiones y manifestaciones sensoriales que reflejen en el gesto el auténtico "pathos" de una "dramaticidad cristiana". ${ }^{35}$ Ese "pathos

${ }^{32}$ Como afirma San Ignacio en el primer preámbulo del apartado 47, perteneciente al "Primer exercicio es meditación con las tres potencias sobre el $1^{\circ}, 2^{\circ}$ y $3^{\circ}$ pecado; contiene en si, después de una oración preparatoria y dos preámbulos, tres puntos principales y un coloquio": "El primer preámbulo es composición viendo el lugar. Aquí es de notar, que en la contemplación o meditación visible, así como contemplar a Christo nuestro Señor, el qual es visible, la composición será ver con la vista de la imaginación el lugar corpóreo, donde se halla la cosa que quiero contemplar. Digo el lugar corpóreo, así como un tempo o monte, donde se halla Jesu Christo o nuestra Señora, según lo que quiero contemplar". Ejercicios Espirituales, en Obras de Ignacio de Loyola, 2012, Ediciones La Biblioteca Digital, Pos. 1099-1100.

${ }^{33}$ Perla Chinchilla Pawling, De la Compositio Loci a la República de las Letras, 2004, México, El Mundo, p. 145.

${ }^{34}$ Una figura retórica que será clave para entender lo que pretende San Ignacio será la hypotyposis, "la cual sirve a la mente para visualizar lo sobrenatural, y así poder ser conmovido por ello" Perla Chinchilla Pawling, "La retórica de las pasiones. La predicación en el siglo XVII", Historia y Grafia, 7, 1997, pp. 93-124 (esp. p. 112). Se trata de una figura que aúna lo abstracto con lo sensorial con una viveza tal, que permite el ascenso hacia la imagen y conocimiento de lo divino. Como definen Marchese y Forradellas (Diccionario de retórica, crítica y terminología literaria, 2013, Madrid, Ariel, p. 199): "normalmente sirve para expresar caracteres de naturaleza abstracta con rasgos perceptibles por los sentidos, e incluso, algunas veces, como señala Dupriez, alucinatorios".

${ }^{35}$ Bolívar Echeverría (op. cit., pp. 75-77) pone como ejemplo de la "dramaticidad cristiana" en un entorno pagano la obra de Bernini, cómo el rostro de Dafne refleja el misticismo religioso 
ingenioso" es lo que Gracián denominará "agudeza de ingenio"36 y que abordará en todo un tratado: Agudeza y arte de ingenio. ${ }^{37}$ Para Gracián, de hecho, el verdadero Cicerón es el de su primera época, el de Pro Fonteio ("en todo género de agudeza fue excelente"), porque luego se atempera: "tiene también eminente lugar entre los ingeniosos y agudos, aunque como orador se templaba y como filósofo ejercitaba más el juicio que el ingenio". 38

Según Bolívar Echeverría, ese ingenium barroco, o mejor dicho esa agudeza de ingenio, si seguimos a Gracián, exprimirá el clasicismo, herido de muerte, del humanismo renacentista y le sacará un último jugo, retorciéndolo hasta sus últimas consecuencias, y empleará el ingenium para sacar la savia y el espíritu "auténtico" de los autores clásicos a los que los renacentistas no supieron llegar. Los jesuitas barrocos intentan "despertar la vitalidad del gesto petrificado"39 o el "drama que dormita en el orden de las proporciones clásicas"40 del arte y de los textos clásicos, ya que hay que "buscar y encontrar el conflicto que se esconde en la perfección de su mesura". ${ }^{41}$ Para que ese ingenium adquiera el sentido jesuítico vital y educativo ha de ser exprimido hasta sus últimas consecuencias, con el propósito de ahondar y contemplar los misterios de Dios en la naturaleza, que nunca lograrán entenderse totalmente y que producirá una angustia vital, que a su vez refleja la "inconclusión" del ser humano, que siempre necesitará a Dios para sentirse más completo, sin llegar a la perfección de lo divino. El único modo de hacerlo será, en palabras de Bolívar Echeverría, provocando "una proliferación de subformas parasitarias que, al rodear a una determinada forma y revolotear en torno a ella, la someten a un juego

de su santa Teresa. Precisamente esa dramaticidad es la que jesuitas pretenderán transmitir a los autores clásicos.

${ }^{36}$ C. Ma. Martini, "Los ejercicios y la educación estética”, en “Arte y espiritualidad jesuitas”, Artes de México, 70, 2004, pp. 8-15, (esp. p. 9).

${ }^{37}$ Edición de 1648, que será la definitiva. La primera se publicó en 1642, con el título de Arte de ingenio. Tratado de la agudeza.

${ }^{38}$ Gracián, Agudeza y arte de ingenio, El criticón, El discreto, en Obras Completas, 1967, Madrid, Aguilar, p. 505.

${ }^{39}$ Echeverría, op. cit., p, 46.

${ }^{40}$ Ibid., p. 93.

${ }^{41}$ Ibid., p. 94. 
de reflejos multiplicados que la potencien virtualmente, la obligan a dar más de sí, a encontrar la fidelidad a su designio profundo". ${ }^{42} \mathrm{De}$ este modo, el ingenium ciceroniano, en su enfoque barroco, recupera la celeritas de la retórica ciceroniana y la transforma en "agudeza", de modo que, potenciada por el pathos católico-jesuita y manifestada a través del ornamento de las figuras retóricas, "epistémicamente necesarias", ${ }^{43}$ alimenta la fides que sostiene la sociedad del antiguo régimen. De este modo, el elemento de la fides que expresaba la retórica ciceroniana como instrumento de unión con la sociedad, era para los jesuitas el elemento de unión con la Iglesia que, a su vez, mantenía coordinada a la sociedad. ${ }^{44}$ Hasta aquí podemos apreciar que el ingenio ciceroniano se vuelve "agudeza de ingenio" barroco.

A partir de la revolución cartesiana entre finales del siglo XVII y la primera mitad del XVIII, este concepto dará la vuelta radicalmente $\mathrm{y}$ veremos que el ingenio pasa de ser agudo a ser decoroso. Con el pensamiento racionalista se recupera el equilibrio de ingenio que preconizaba Cicerón y que durante el barroco jesuita se había perdido. De este modo, la Ilustración cartesiana envuelve el ingenium con el corsé de la ratio (razón) y de "aguda" se vuelve "decorosa" y "racional". El pensamiento cartesiano se basa en dos directrices fundamentales de Les Principes de la philosophie: el método filosófico y de conocimiento ha de asentarse en un razonamiento "claro" y "distinto". ${ }^{45}$ Según esto, podríamos pensar que el ingenium retorna a la esencia del concepto real del "decoro" ciceroniano; no obstante, esto no es así del todo. Si bien en la teoría los ilustrados pretenden retornar a esa esencia, en la práctica acaban ideologizando y llevándolo a sus cosmovisiones particulares.

Así pues, debido a la influencia del método de Descartes, que se aplicará didácticamente en los colegios jansenistas de Port-Royal, la

${ }^{42}$ Ibid., pp. 88-89.

${ }^{43}$ Chinchilla Pawling, op. cit., núm. 34, p. 118.

44 “La exteriorización de las prácticas como factor de pertenencia a la Iglesia fue cada vez más evidente, en tanto que puede verse cómo la experiencia religiosa se recogió hacia el espacio de la interioridad del sujeto". Ibid., núm. 34, p. 119.

${ }^{45}$ "La connaissance sur laquelle on peut établir un jugement indubitable doit être non seulement claire, mais aussi distincte", Descartes I, Articles 43 y 45; R. Descartes, Les Principes de la philosophie, 1647, en <http://www.cde4.com/fra/respedago/philosophie/1631.htm>. 
retórica ciceroniana se conjugará con la lógica cartesiana ${ }^{46}$ hasta el punto de que se empezarán a estudiar en conjunto: la primera acabará por configurar a la segunda. De este modo, la "agudeza de ingenio" que acabó por dirigir la estructura y la aplicación de la retórica ciceroniana se convertirá en el bon sens de la razón algebraica y matemática cartesiana, que reordenó la retórica. ${ }^{47}$ Ya no tendrán tanta importancia las figuras estilísticas de la elocutio que acrecientan la agudeza barroca, sino que se destacarán tanto la argumentatio, como la dispositio, que se convertirán en los principales instrumentos de la razón del bon sens. El decorum ciceroniano se acerca al logos aristotélico, pero en su vestimenta cartesiana, de modo que se sustituye por una razón distinguidora y clarificadora. Las figuras seguirán teniendo relevancia en el método cartesiano port-royalista, pero serán aprendidas desde una perspectiva lógico-semántica que permite clarificar la razón oculta de la composición y estructura de estas. ${ }^{48}$ La razón en el ingenio se volverá progresivamente un poderoso obstáculo para desarrollar la imaginación y un sentimiento fresco y espontáneo. En ese aspecto, vemos que pasamos al otro extremo del péndulo, de un ingenium excesivamente marcado por la imaginación y fantasía, en el barroco, a otro excesivamente cargado de reglas racionales que lo maniatan. El ingenium se volverá frío y lógico, muy influido por el método logicista cartesiano.

Se necesitará la influencia posterior del empirismo y su revitalización del sensus para que la retórica retome un ingenium más libre, menos lógico y más ecuánime con los sentimientos y afectos sensoriales del ser humano. De este modo, los ilustrados franceses del XVIII, los sensoempiristas (Condillac, Dumarsais, etc.), que conjugarán cartesianismo con empirismo, volverán al decorum ciceroniano y el bon sens se convertirá en una especie de ingenium decoroso, que se podrá denominar como bon goût, ${ }^{49}$ el cual regirá todas las artes, desde las artes decora-

${ }^{46}$ Un estudio detallado de la lógica cartesiana de Port-Royal a través de la obra de Arnauld, es el de C. Senofonte, Ragione moderna e teología l'uomo di Arnauld, 1989, Nápoles, Guida Editori, pp. 273-320.

${ }^{47}$ Ibid., pp. 274-276.

${ }^{48}$ Así, el ideólogo ilustrado y enciclopedista Dumarsais analizará las figuras según su semántica en su Traité de Tropes, pour servir d'introduction à la rhetorique et à la logique (1757).

${ }^{49} \mathrm{El}$ equilibrio entre el plano lógico, sensitivo y ético desarrollará lo que se ha denominado goût o bon goût. Junto a todas las influencias filosóficas y sociales, no podemos olvidarnos de 
tivas hasta la misma literatura. ${ }^{50}$ De este modo, el bon goût acabará volviéndose un ingenium ecléctico que sobre la base del decorum ciceroniano superará el bon sens frío y lógico de Descartes y asumirá la sensibilidad sentimental proveniente del empirismo, sin caer en el pathos jesuita; en definitiva, una sensibilidad decorosa, controlada por una lógica sensibilizada.

Pero si esto es así en el terreno artístico-literario, el decorum ciceroniano del ingenium será empleado de modo más directo por los ilustrados en su vertiente ético-social, que se caracterizará por la virtus ética. Es decir, el ingenium de Cicerón es la base de una sociedad entrelazada por una fides y un labor virtuoso. Por ello mismo, autores como Montesquieu, Rousseau o el español Gaspar Melchor de Jovellanos tomarán el ingenio como el soporte racional y decoroso de una naturaleza humana que ha de ser educada en la virtud y la honestidad, con el fin de formar buenos ciudadanos que transformen o "revolucionen" la sociedad. El ingenio virtuoso ilustrado, que tiene como base el que preconiza Cicerón, adquirirá tintes ideológicos para defender un tipo de sociedad de progreso en la razón y la ciencia que rompa definitivamente con la sociedad de la oscuridad y del engaño barroco del antiguo régimen. Cicerón será citado prácticamente por todos los ilustrados y se convertirá en el soporte de los nuevos ciudadanos que deberán pensar desde la "óptica ingeniosa de la razón".

El amor público que tanto van a defender los ilustrados será el equivalente del ingenium social ciceroniano y encierra todos los conceptos de labor, officium, fides y decorum. En prácticamente todos los ilustrados, la alambicada línea ciceroniana de engarce social se vuelve “amor", y desde un principio más "sentimental”, que en Cicerón servirá

la impronta destacada del Arte Poética (1674) de Nicolás Boileau (1636-1711), que revitalizará los principios básicos del Arte Poética horaciana de equilibrio, pureza y belleza armónica. Estos factores influirán poderosamente sobre la configuración de la estética del bon goût y lo veremos, con más detalle, expresados en la obra de Batteux.

${ }^{50}$ Aquí es donde se producirá una escisión entre la retórica que direccionado hacia su lado reflexivo y argumentativo tiende a la lógica, y la retórica que aliada con la poética y donde se requiere más del plano sentimental tiende a analizar las manifestaciones literarias y se convertirá en la base de la futura historia de la literatura. Sobre esta reconfiguración de la retórica, véase J. Espino, "La enseñanza de la literatura clásica. Retórica, poética y comparatismo", Analecta Malacitana, Anejo 51, 2005, pp. 27-46. 
para asentar las bases sociales de forma más solida. De este modo, el amor sustituye al deber, al decoro o al ingenio. Este concepto de "amor" proviene fundamentalmente del amor a la república y a las leyes, de Montesquieu $^{51}$ o de la emotividad sentimental de amor a la sociedad en Rousseau. En definitiva, el "amor público"y “civil” es, en palabras de Jovellanos, la base de todos los conceptos que para Cicerón se dan en la comunión social: "unidad civil", "deberes y funciones" que corresponde a cada individuo, "respeto a la constitución", "obediencia a las leyes", "orden", "tranquilidad", "prosperidad" y "felicidad de cada ciudadano" (conceptos todos ellos que se repiten a lo largo de todas las obras de Cicerón, pero especialmente en el De Officiis).

A partir de la segunda mitad del XVIII se produce un triunfo progresivo del empirismo y, en Francia, del senso-empirismo que pretende aunar cartesianismo y empirismo. Sus ideólogos verán en el ingenium el soporte para el equilibrio entre el lado racional y sensorial o sentimental, por lo que se empezará a concebir el sentimiento como parte importante de la mente humana a la hora de tomar decisiones de carácter lógico. De ese modo, el péndulo de nuevo va a dar un giro de forma que del ingenio racional y lógico pasamos al ingenio del sentir.

${ }^{51}$ Ya Cicerón utilizó el concepto de amor patrice, pero será Montesquieu quien, en su apartado "Amor social, como virtud principal de la República" del comienzo del Libro I, Del espíritu de las leyes, dará especial énfasis a este concepto, del que afirma los siguiente: "En el gobierno republicano es donde se necesita de todo el poder de la educación. El temor de los gobiernos despóticos se engendra espontáneamente en las amenazas y los castigos; el honor de las monarquías es favorecido por las pasiones, que, á su vez, fomenta; pero la virtud política consiste en la abnegación de sí mismo, cosa siempre muy penosa. Puede definirse esta virtud como el amor de las leyes y de la patria, el cual, pidiendo que se prefiera de continuo el interés público al propio, inspira todas las virtudes particulares, que no son sino esa preferencia. Este amor es peculiar de las democracias. En estas solamente se confía el gobierno á todos los ciudadanos. Ahora bien, con el gobierno pasa lo que con todas las cosas del mundo: para conservarlo es menester amarlo. Nunca se ha oído decir que los reyes no amasen la monarquía ni que los déspotas aborreciesen el despotismo. Todo depende, pues, de que este amor arraigue en la república, y la educación debe dirigirse á inculcarlo. Pero hay un medio para que los niños puedan tenerlo: es que sus padres lo tengan. Somos dueños de ordinario de dar á nuestros hijos nuestros conocimientos: lo somos aún más de comunicarles nuestras pasiones. Si esto no sucede, es porque la labor del padre ha sido destruida por las impresiones del exterior. El pueblo que empieza á nacer no degenera: no se pierde sino cuando los hombres formados están ya corrompidos.” Barón de Montesquieu, El espíritu de las leyes, tomos I y II, 1906, Madrid, Librería General de Victoriano Suárez, trad. de Siro García del Mazo, pp. 56-57. 
Por lo tanto, el goût sensista pretenderá restaurar la pureza y el equilibrio senso-racional de la retórica grecolatina, ${ }^{52}$ como harán los trabajos retóricos y estéticos del escocés Hugo Blair, el cual se opondrá a la "agudeza de ingenio" barroco, pero también a un exceso logicista del ingenio que se pudo dar en las primeras décadas del siglo XVIII de influencia única cartesiana. ${ }^{53}$

Este será la puerta abierta para una progresiva sensorialización o sensibilización del ingenio que dará pie al ingenio poético y emotivo del prerromanticismo y del futuro Romanticismo. ${ }^{54}$

\section{Conclusiones}

El concepto de ingenium que Cicerón plantea en sus obras retóricas muestra un modo de interpretar la realidad basado en la verosimilitud, frente a la verdad que sostiene el logos philosophicus aristotélico. Según esto, el ingenium desarrolla instrumentos de engarce social como son la labor, la fides o la celeritas que permiten sostener la sociedad dentro de una estructura superior tanto política, como estatal. La retórica contiene todo este entramado a través del ingenium que se manifiesta en discursos emitidos en diversos foros públicos y que, indudablemente, contribuyen a organizar toda la jerarquización social. Aunque el ingenium

${ }^{52}$ Hugo Blair, en su capítulo V "De la elocuencia romana" dedicado a Cicerón, dice que los mayores "defectos" del Arpinate están en sus "primeros tiempos", donde "hay mucho arte, y este encaminado al luzimiento", "visiblemente hace alarde de su elocuencia", se preocupa "más de captarse la admiración de los oyentes, que de convencerlos" y en ocasiones es más pomposo que solido" y es "difuso, cuando debiera ser conciso". Véase Blair, Compendio de las lecciones sobre la retórica y bellas letras de Hugo Blair, 1815, Madrid, Imprenta de Ibarra, trad. de José Luis Munárriz, pp. 196-197. Con ello, el intelectual escocés muestra el repudio por el Cicerón artificioso de la primera época que, sin embargo, placía profundamente al jesuita Gracián.

${ }^{53}$ El gusto busca la belleza por el equilibrio, como al niño le agradan los "cuerpos regulares". Con ello, Blair se va decantando por el lado más sentimental que racional del gusto, como efecto de un equilibrio retórico y lógico. De este modo, del "gusto" estético, racional y objetivo, propio del sensismo francés, Blair lo dirige hacia un gusto personal, causante de un placer individual, que sobre presupuestos racionales "nos hace gozar"; ibid., p. 10.

54 “En tanto las pasiones y la emotividad, 'por una extraña alquimia' de la cultura, fueron quedando inscritas en el espacio de la literatura, la poesía y el Romanticismo en concreto, son herederos de la Retórica las pasiones"; Chinchilla Pawling, op. cit., p. 124, n. 34. 
debe potenciarse con la imaginatio, que se manifiesta especialmente a través de las figuras retóricas (especialmente, la metáfora) no debe verse esta desbordada por la phantasia, por lo que un tipo de razonamiento social y retórico, el decorum, le servirá de guía y control para no caer en los extremismos y excesos.

Cuando los jesuitas adoptan el ciceronianismo como método educativo, heredan todo este pensamiento retórico, superando el intelectualismo en que Cicerón había caído en el Renacimiento, y le confieren un elemento pasional, un pathos religioso que potencia la celeritas de la retórica ciceroniana y la transforma en "agudeza", de forma que la imaginatio se explaya y llega a los límites de la phantasia. De este modo, los jesuitas consideran que en lo que Cicerón se había quedado corto, ellos lo amplían gracias a la pasión y un profundo sentimiento cristiano que el Arpinate no tenía. Precisamente en este aspecto, los jesuitas se consideran superiores al orador romano, puesto que consideran que gracias a la visión cristiana, en alianza con el armazón retórico ciceroniano logran ahondar y comprender los misterios de la divinidad insertos en la naturaleza.

En el siglo XVIII, a causa del método cartesiano se produce un giro copernicano (y nunca mejor dicho) de toda esta realidad y la retórica se comprende y aplica en cuanto al método logicista científico. Ahora no es la celeritas de la "agudeza del ingenium" la que se potencia, sino el decorum, que no se percibe tanto como una ratio retórica, sino como más cercano al logos philosophicus aristotélico, que a partir de la segunda mitad del XVII se convertirá en el bon sens del método cartesiano. El decorum visto a través del bon sens se convierte en bon goût, cuando el senso-empirismo del siglo XVIII entra en acción y el ingenium racionalista de la primera Ilustración cartesiana va transformándose en un ingenium más "sensibilizado", más abierto al mundo de los sentimientos y de la afectividad. Este ingenium se convertirá en la puerta abierta al sentimentalismo prerromántico, que con el cambio de centuria se amplificará en el pathos decimonónico, ya no tanto el religioso de los jesuitas, cuanto el lírico y metafísico de los poetas románticos del siglo XIX. 